\title{
Hospital Based Study of Poisoning Among Children, 1 to 18 Years of Age in Eastern Nepal
}

\author{
Rimal $H S{ }^{1}$ Tiwari $U^{2}$ Ghimire $K^{3}$ Thapa $M^{4}$
}

\section{Affiliation}

1. Associate Professor, Department of Paediatrics, Birat Medical College \& Teaching Hospital, Biratnagar, Nepal

2. Bahrabise, Primary Health Care Centre, Sindhupalchowk

3. Bhimphedi, Primary Health Care Centre, Makwanpur

4. Salyan, Primary Health Care Centre, Solukhumbu

\section{ARTICLE INFO}

\section{Article History}

$\begin{array}{lll}\text { Received } & : & 3 \text { April, } 2017 \\ \text { Accepted } & : & 25 \text { April, } 2017 \\ \text { Published } & : & 30 \text { April, } 2017\end{array}$

(C) Authors retain copyright and grant the journal right of first publication with the work simultaneously licensed under Creative Commons Attribution License CC - BY 4.0 that allows others to share the work with an acknowledgment of the work's authorship and initial publication in this journal.

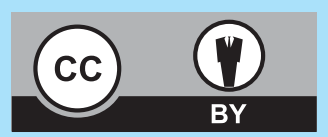

ORA 21

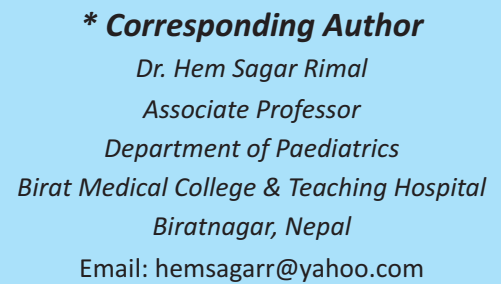

\section{Citation}

Rimal HS, Tiwari U, Ghimire K, Thapa M. Hospital Based Study of Poisoning Among Children, 1 to 18 Years of Age in Eastern Nepal. BJHS 2017; 2 (1) 2:138-141.

\section{ABSTRACT}

\section{Introduction}

The poisoning among children had been a major cause of hospital admission and also a significant global health problem throughout the world including Nepal. There are various studies suggestive of incidence rate of poisoning in children ranging from $0.74 \%$ to $3 \%$. In older children, poisoning is usually intentional where as in infants and younger children it is accidental in nature There are few studies done in Nepal and they are mainly from Kathmandu valley, this study will add more information from eastern region of Nepal.

\section{Objective}

This study aimed to find out the type of poisoning among children and adolescents, manner of poisoning and its outcomes.

\section{Methodology}

This was a retrospective study carried out at Nobel Medical College Teaching Hospital over a period of one year starting from $1^{\text {st }}$ August 2014 to $31^{\text {st }}$ July 2015 . This study included all the children and adolescents of 1 to 18 years of age admitted to pediatric ward and ICU for the management of poisoning. The information including name of poisons, manner of poisoning, socio-economic and demographic factors related to poisoning, geographical distribution of sample population, durations of hospital stay and outcome of treatment were retrieved from the records. The data was analyzed using SPSS.

\section{Results}

A total of 64 cases were studied. It included almost the same number of males $(n=31)$ and females $(n=33)$. The age group of 13-18 years had the largest prevalence of poisoning $(n=22)$. Organo-phosphorus $(n=25)$ was the commonest poison. As the study was conducted in a tertiary care center of eastern Nepal located at Biratnagar, Morang district, a majority of the cases (39) were from Morang. A total of $41 \%$ children required hospital stay for more than 7 days where as $37 \%$ of them required 5-7 days of hospital stay and only $22 \%$ children stayed for 1-4 days in the hospital. No mortality was noted.

\section{Conclusion}

The pediatric poisoning in eastern Nepal is a significant public health issue and nature of poisoning was accidental followed by suicidal. The commonest age group involved is adolescence, which highlights the need for education and implementation of suicidal prevention programin this region. The higher prevalence of accidental poisoning in first two year of life necessitates the need of child safety and injury prevention program in the community.

\section{KEYWORDS}

Child safety, Nepal, poisoning, suicide prevention 


\section{INTRODUCTION}

Poisoning among children had been a major cause of hospital admission and a significant global health problem throughout the world including Nepal. ${ }^{1,2}$ There are various studies suggestive of incidence rate of poisoning in children ranging from $0.74 \%$ to $3 \% .^{3.9}$ In older children poisoning is usually intentional whereas in infants and younger children it is accidental in nature. ${ }^{10,11,12}$

According to World Health Organisation (WHO), in the year 2004 an estimated 346,000 people died worldwide from unintentional poisoning. Of these deaths, $91 \%$ occurred in low and middle income countries. Most of the poisonings take place in rural areas of developing countries, where safeguards typically are inadequate or lacking altogether. There is a growing concern regarding the unregulated use of pesticides in the field of agriculture. Although the developing countries use $25 \%$ of the world's production of pesticides, they experience $99 \%$ of the deaths due to pesticide poisoning. ${ }^{13}$

According to $\mathrm{WHO}$, the suicidal rate is increasing and more children and adolescents are having increasing number of stressors on daily life that could lead to more self-harm using poisons available. The pattern of poisoning is dynamic and differs a lot according to time and from country to country as well. ${ }^{11}$ Hence, epidemiological surveillance of each country and also the different regions within the country is an important public health activity to bring up preventive programs in the country which is possible after having adequate and reliable data from the representative population. This study has been designed to generate this data. Poisoning in children is one of the common cause of hospital admission in Nepal. There are few studies done in Nepal and they are mainly from Kathmandu valley, this study will add more information from eastern region of Nepal, which is quite different socio culturally and demographically from central and other part of Nepal. This study will be helpful to make strategic planning for the prevention of poisoning among children.

\section{METHODOLOGY}

This study was carried out at Nobel Medical College Teaching Hospital (NMCTH), Biratnagar, Nepal during a duration of one year, i.e. from 1st August 2014 to 31st July 2015. The study population was composed of cases admitted to the pediatric ward, PICU and emergency department, all of which were from the age group of 1-18 years of age. The study was conducted by doing a retrospective view of the records of the cases of pediatric poisoning of (1-18years) cases, admitted at NMCTH, Biratnagar at the specified time period of the study. Patients with a mild sting, which didn't require admission, were excluded from the study. The sample size of the study was dependent on the number of total admissions but it was expected to be at least 60 cases. Pre testing was done by looking at the discharge record from the pediatric ward and data was retrieved and discussed among the co-authors. The data was entered in MS Excell and later transferred into SPSS for further analysis. The details about the poison including name of poisons, manner of poisoning, socio-economic and demographic factors related to poisoning, geographical distribution of population, durations of hospital stay, outcome of treatment and preventive aspect of poisoning were retrieved from the records.

The analyzed data were presented in the table and figures in an appropriate manner. All quantitative variables were expressed as the median and standard deviation, while qualitative variables were expressed as frequencies and percentages. The association among variables with type of poisoning and outcome was measured. Ethical clearance was obtained from the Institutional Review Committee of the Nobel Medical College Teaching Hospital, Biratnagar, an accredited body of Nepal Health Research Council.

\section{RESULTS}

Table 1 shows the socio-demographic profile of the study population $(n=64)$ that included $52 \%$ female and rest were male. The maximum number of cases were in the age of 1318 years ( $34 \%$ ) and the lowest (13\%) were in 6-12 years age group. Major ethnicity was Madhesi (41\%).

The majority of cases were from Morang district (61\%) that is followed by Sunsari (16\%), Saptari (9\%), Siraha (6\%) and also from India (8\%). Majority of cases were from Morang district as the hospital is located in Biratnagar which is the headquarter of Morang district. As in figure 1, the majority of children (78\%) were from low socio-economic status family.

\section{Table 1: Socio-demographic profile of the study} population $(n=64)$

\begin{tabular}{|lcc|}
\hline Variables & Number of cases & Percentage \\
\hline Age group (Years) & & \\
\hline $1-2$ & 21 & 33 \\
\hline $3-5$ & 13 & 20 \\
\hline $6-12$ & 8 & 13 \\
\hline $13-18$ & 22 & 34 \\
\hline Sex & & \\
\hline Male & 31 & 48 \\
\hline Female & 33 & 52 \\
\hline Ethnicity & & \\
\hline Madheshi & 26 & 41 \\
\hline Bramhin /Chhetri & 11 & 17 \\
\hline Janajati & 9 & 14 \\
\hline Muslim & 5 & 8 \\
\hline Dalit & 3 & 5 \\
\hline Others & 10 & 15 \\
\hline
\end{tabular}


Table 2 shows that the most common type of poisoning was organo-phosphorous poisoning (39\%) which was followed by kerosene poisoning (23\%) and $12 \%$ had others poisoning which ayurvedic medication, dettol, olanzepine, rat poison, oleander, zalim lotion and wasp bite. The commonest manner of poisoning was accidental (58\%) in nature.

As in table 3, 41\% children required hospital stay for more than 7 days where as $37 \%$ required 5-7 days of hospital stay and only $22 \%$ children stayed for $1-4$ days. The outcome of the hospital admission of cases revealed that the total discharge, discharge on patient request(DOPR), leave against medical advice(LAMA) were $81 \%, 8 \%$ and $11 \%$ respectively. No mortality was noted at the hospital.

\section{Table 2: Manner and Types of poisoning}

\begin{tabular}{|lll|}
\hline $\begin{array}{l}\text { Variables } \\
\text { Manner }\end{array}$ & Number of cases & Percentage \\
Suicidal & 27 & 42 \\
\hline Accident & 37 & 58 \\
\hline Type of Poison & & 39 \\
\hline Organophosphorus & 25 & 23 \\
\hline Kerosene & 14 & 9 \\
\hline Dhatura & 6 & 12 \\
\hline Unknown & 9 & 3 \\
\hline Benzodiazepine & 2 & 12 \\
\hline Unknown & 8 & 3 \\
\hline Castor seed & 2 & \\
\hline
\end{tabular}

Figure 1: Socio Economic status of child family $(n=64)$

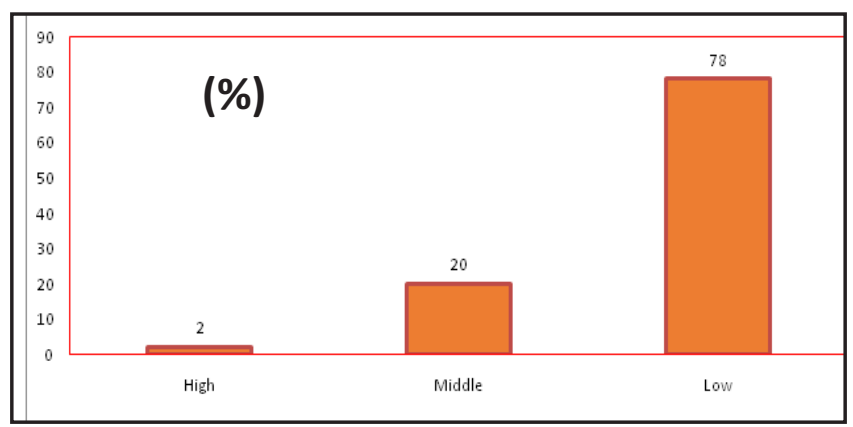

Table 3: Duration of hospital stay and outcome $(n=64)$

Variable Number Percentage

\section{Duration of hospital Stay (days)}

\begin{tabular}{lll}
\hline $1-4$ & 14 & 22 \\
\hline $5-7$ & 24 & 37 \\
\hline$>7$ & 26 & 41 \\
\hline Outcome of cases & & \\
\hline Discharge & 52 & 81 \\
\hline DOPR & 5 & 08 \\
\hline Lama & 7 & 11
\end{tabular}

\section{DISCUSSION}

The most vulnerable groups for pediatric poisoning are found to be different in different studies. Study done by Sadeghi Bojd et al found that poisoning was most common among children younger than 5 years. ${ }^{14}$ According to Rashid M.M et al, 1-3 years age group was the most vulnerable age group for pediatric poisoning, observed in the Khulna Medical College Hospital in Bangladesh. ${ }^{2}$ However, in our study the most vulnerable groups were 13-18 years. The second most vulnerable age group was found to be $1-2$ years age group. The poisoning cases were almost equally distributed and similar finding was observed by Khadga SB et al in a study done at Kathmandu Medical College Teaching Hospital. ${ }^{15}$ In our study more than three quarters of children belonged to lower socio economic status which is similar to the findings from Karki A et al. ${ }^{16}$ The majority of children were from Morang district and the commonest ethnicity of the children was Madhesi which is consistent with the population distribution in the region. We also received five poisoning cases from our neighbouring country India.

While looking at the trend of pediatric poisoning, we noted that the poisoning was accidental in nature in $58 \%$ and suicidal in $42 \%$ of children. This finding is different from the finding of UD Chhetri et al in Patan Hospital where $76 \%$ were accidental and only $18 \%$ were suicidal. This study really highlights the need of more suicidal prevention program in this region. The organophosphorus poisoning was the most common poison involved, followed by kerosene poisoning and the commonest route of administration was oral. A study done by Ram P et al $^{17}$ in South India found kerosene poisoning and organophosphorus poisoning to be the two most common poisons involved, similarly Chaudhary FR et $\mathrm{al}^{18}$ in Bangladesh also noted organophosphorus poisoning to be the commonest poison used, both of which share stark similarities with our findings. The third most prevalent poison was Dhatura $(n=6)$. There were significant number of children $(n=9)$ where we could not accurately identify the poison. The others category of poison included one case each of Ayurvedic medication, dettol, olanzepine, phenol, rat poison, oleander, zalim lotion and wasp bite. These are quite a variety of drugs and poisons.

The duration of hospital stay in poisoning varies depending upon the type of poisons used, health condition of the patients at the time of hospital admission and the necessity of intensive care support. In our study, $41 \%$ of children stayed for more than seven days while $37 \%$ stayed for 5-7 days and only $22 \%$ stayed for 1-4 days. In terms of outcome of management, $81 \%$ were discharged, $11 \%$ went home on leave against medical advice(LAMA) and $8 \%$ were taken home on discharge on parents request (DOPR). There was no mortality in the hospital. Since we couldn't follow up DOPR 
and LAMA category of patients we are assuming that there might have been some mortality at home.

\section{CONCLUSION}

The pediatric poisoning in eastern Nepal is a significant public health issue and nature of poisoning was accidental followed by suicidal. The commonest age group involved is adolescence, which highlights the need for education and implementation of suicidal prevention programin this region. The higher prevalence of accidental poisoning in first two year of life necessitates the need of child safety and injury prevention program in the community.

\section{REFERENCES}

1. Paudyal BP. Poisoning: pattern and profile of admitted cases in a hospital in central Nepal. JNMA 2005;44(159):92-6.

2. Rashid MM, Hasan MA, Chowdhury FR. Childhood acute poisoning in a tertiary medical college hospital of Bangladesh. Mymensingh Med J. 2007;16(2 Suppl):S12-4.

3. Sahin S, Carman KB, Dinleyici EC. Acute poisoning in children; data of a pediatric emergency unit. Iranian journal of pediatrics. 2011;21(4):479-84

4. Koliou M, loannou C, Andreou K, Petridou A, Soteriades ES. The epidemiology of childhood poisonings in Cyprus. European journal of pediatrics. 2010; 169(7):833-8.

5. Koueta F, Dao L, Ye D, Fayama Z, Sawadogo A. Acute accidental poisoning in children: aspects of their epidemiology, aetiology, and outcome at the Charles de Gaulle Paediatric Hospital in Ouagadougou (Burkina Faso). Sante (Montrouge, France). 2009;19(2):55-9.

6. Burillo-Putze G, Munne P, Duenas A, Pinillos MA, Naveiro JM, Cobo J, et al. National multicentre study of acute intoxication in emergency departments of Spain. European journal of emergency medicine 2003;10(2):101-4.

7. Oguche S, Bukbuk DN, Watila IM. Pattern of hospital admissions of children with poisoning in the Sudano-Sahelian North eastern Nigeria. Nigerian journal of clinical practice. 2007;10(2):111-5.

8. Buch NA, Ahmed K, Sethi AS. Poisoning in children. Indian pediatrics. 1991;28(5):521-4.

9. Chhetri UD, Ansari I, Shrestha S. Pattern of pediatric poisoning and accident in Patan Hospital. Kathmandu Univ Med J (KUMJ). 2012;10(39):39-43.

\section{RECOMMENDATIONS}

Keeping in mind the inquisitive and explorative nature of children while they grow, parents need to be aware of keeping hazardous things and medicines etc. out of reach of children. All the drugs must be locked in bottle that has child safety lock. Caregivers and parents must be educated about the preventive strategies that include the education of caregivers on the handling of medications and household products. At the policy level, legislation requiring child resistant packaging for all medications and household products must be enacted. As organophosphorus poisoning clearly is the most common poison used, the regulation of the use of pesticides must be well enacted.

10. Lamireau T, Llanas B, Kennedy A, Fayon M, Penouil F, FavarellGarrigues JC, et al. Epidemiology of poisoning in children: a 7-year survey in a paediatric emergency care unit. European journal of emergency medicine. 2002;9(1):9-14.

11. Andiran N, Sarikayalar F. Pattern of acute poisonings in childhood in Ankara: what has changed in twenty years? The Turkish journal of pediatrics. 2004;46(2):147-52.

12. Dutta AK, Seth A, Goyal PK, Aggarwal V, Mittal SK, Sharma R, et al. Poisoning in children: Indian scenario. Indian journal of pediatrics. 1998;65(3):365-70.

13. World Health Organization, 2004. Available at http://www. who.int/ceh/capacity/Pesticides.pdf

14 Sadeghi-Bojd S, Khajeh A. Chronological variations of children poisoning causes in zahedan, South of iran. International journal of high risk behaviors \& addiction. 2014;3(3):e19223.

15. Khadka SB, Khadka SB. A study of poisoning cases in emergency Kathmandu Medical College Teaching Hospital. Kathmandu Univ MedJ (KUMJ). 2005;3(4):388-91.

16. Karki RK, Risal A. Study of poisoning cases in a tertiary care hospital. Kathmandu Univ Med J (KUMJ). 2012;10(40):70-3.

17. Ram P, Kanchan T, Unnikrishnan B. Pattern of acute poisonings in children below 15 years: a study from Mangalore, South India. Journal of forensic and legal medicine. 2014;25:26-9.

18. Chowdhury FR, Rahman AU, Mohammed FR, Chowdhury A, Ahasan HA, Bakar MA. Acute poisoning in southern part of Bangladesh-the case load is decreasing. Bangladesh Medical Research Council bulletin. 2011;37(2):61-5. 